Proceedings of the 33rd Annual Meeting of the Brazilian Embryo Technology Society (SBTE); Ilha de Comandatuba, BA, Brazil, August 15th to 19th, 2019.

\title{
Embryo competence and cryosurvival: Molecular and cellular features
}

\author{
Thamiris V. Marsico ${ }^{1}$, Janine de Camargo ${ }^{2}$, Roniele S. Valente ${ }^{1}$, Mateus J. Sudano ${ }^{1,2, *}$ \\ ${ }^{1}$ Center for Natural and Human Sciences, Federal University of ABC, Santo André, SP, Brasil. \\ ${ }^{2}$ School of Veterinary Medicine, Federal University of Pampa, Uruguaiana, RS, Brasil.
}

\begin{abstract}
Global cattle genetic market is experiencing a change of strategy, large genetic companies, traditionally recognized in the artificial insemination field, have also begun to operate in the embryo market. Consequently, the demand for in vitro produced (IVP) embryos has grown. However, the overall efficiency of the biotechnology process remains low. Additionally, the lack of homogeneity of post-cryopreservation survival results of IVP embryos still impairing a massive dissemination of this biotechnology in the field. A great challenge for in vitro production labs is to increase the amount of embryos produced with exceptional quality after each round of in vitro fertilization. Herein, we discuss the molecular and cellular features associated with the competence and cryosurvival of IVP embryos. First, morphofunctional, cellular and molecular competence of the embryos were addressed and a relationship between embryo developmental ability and quality were established with cryosurvival and pregnancy success. Additionally, determinant factors of embryo competence and cryosurvival were discussed including the following effects: genotype, oocyte quality and follicular microenvironment, in vitro production conditions, and lipids and other determining molecules. Finally, embryo cryopreservation aspects were addressed and an embryofocused approach to improve cryosurvival was presented.
\end{abstract}

Keywords: in vitro production of embryos, bovine, embryo quality, cryopreservation, cryotolerance, pregnancy success.

\section{Introduction}

In the last few years, the importance of in vitro production of embryos (IVPE) has increased within the reproductive biotechnologies applied in dairy and beef cattle. As a consequence, for the first time in the last two decades, the number of in vitro produced (IVP) surpassed the number of in vivo derived (IVD) embryos globally (Fig. 1A).

However, despite the favorable scenario associated with the IVPE, it is important to highlight that even with great effort of the scientific community aimed to improve embryo development and competence in the last decades, the overall efficiency of the biotechnology process remains low (Lonergan et al., 2016; Sudano et al., 2019).
Additionally, embryos derived from in vitro production process generally present a reduced quality compared with the in vivo counterparts (Rizos et al., 2002; Sudano et al., 2012). Consequently, even with important advances in the last years, the cryopreservation of IVP embryos remains as one of the most challenges areas of the embryo technologies since the homogeneity of the achieved results is still not satisfactory. These results impact directly in the reduced number of IVP embryos cryopreserved and transferred to recipients, in relation to the total transferred, when compared with the IVD embryos in the world over the last two decades (Fig. 1B).

Therefore, the objective of this work was to address: i) morphofunctional, cellular and molecular competence of embryos; ii) determinant factors of embryo competence and cryosurvival, including the following effects: genotype, oocyte quality and follicular microenvironment, in vitro production conditions, and lipids and other determining molecules; and iii) embryo cryopreservation aspects and an embryo-focused approach to improve cryosurvival.

\section{Embryo Competence}

It is commonly accepted that in vitro produced (IVP) bovine embryos have lower developmental ability and quality than in vivo-derived (IVD) embryos (Hasler et al., 1995; Sudano et al., 2013a). The embryo developmental ability and quality are two crucial variables associated with cryosurvival, pregnancy establishment and maintenance that can be explained by morphofunctional, cellular and molecular competence of the embryos.

At the present review, the term embryo competence is used to describe the ability of the embryo to develop properly and with an exceptional quality that facilitates cryosurvival and/or pregnancy establishment.

\section{Embryo morphofunctional competence}

Since the establishment of the biotechniques used in assisted reproduction in mammals, a good relationship between morphological evaluation of the embryo quality and pregnancy success after transfer has been established (Lindner and Wright, 1983; Overström, 1996). In most mammalian species, the morphological evaluation of the embryo is the most used method to select embryos suitable for transfer, mainly in cattle and 
humans (Lindner and Wright, 1983; Van Soom et al., 2001). Currently the embryo evaluation system recommended by the International Embryo Technology Society (IETS) is described by Bó and Mapletoft (2013), which classifies the embryos into four quality rankings: (1) excellent or good, (2) regular, (3) bad or (4) dead or degenerate. Drastic changes in embryo's morphology can directly affect its competence.

Assisted reproductive technologies such as in vitro production, nuclear transfer and gene transfer sheds light that imperceptible modifications in embryo structure can seriously compromise its quality. Two classical examples could be cited to illustrate this issue: the silicon/oil used to cover the microdrop culture affects the development of bovine embryos and their cryosurvival according to the product batch; however, embryos produced or not with this oil are morphologically similar. Another example is the parthenogenetic embryo, incapable of producing a successful pregnancy but impossible to be morphologic selected in the blastocyst stage from fertilized embryos (Van Soom et al., 2001).

Since embryos are mostly evaluated when it still confined in zona pellucida (ZP), this structure and the perivitelline space have some importance to discuss. The zona pellucida is a glycoprotein layer produced during oocyte growth phase surrounding the mammalian embryo between the zygote and the blastocyst stage. In average the thickness of $\mathrm{ZP}$ in mammals is $10 \mu \mathrm{m}$ and its ultrastructure characteristics at oocytes (number and diameter of the pores) and embryos (thickness) can be associated with developmental competence (Santos et al., 2008; Báez et al., 2019) and hatching ability (Hoelker et al., 2006), respectively. It's well known that, the ZP thickness decrease further the embryo development (Van Soom et al., 2003) and the average diameter of the ZP is significantly smaller at hatching for IVD versus IVP blastocysts (Holm et al., 2002). Although no relationship between ZP thickness and embryo viability after transfer to recipients was established (Hoelker et a., 2006), the ZP remains crucial for embryo handling before transfer to recipients in the majority of reproductive technologies, and especially, during embryo cryopreservation. Another parameter to be evaluated is the perivitelline space (PS), because it has been recognized that IVD embryos have larger PS than IVP embryos, possibly by the swelling of the blastomeres in the latter. The reduction in size of the PS could be associated with lower embryo quality and related with problems during the morula compaction stage (Van Soom et al., 2003).

Specifically, in the embryo itself, Merton (2002) pointed out some important variables to be considered in the global morphological evaluation, which included: size and shape of blastomeres, presence of extruded or fragmented cells, compaction, color and stage of development which is reached at a certain time after fertilization.

In comparison to humans and mice, all ruminants have a larger accumulation of lipid droplets in the embryo, which cause a quite dark cytoplasm, even darker in pigs, cats and dogs (Van Soom et al.,
2003). This opacity disturbs the possibility of quantification of number of pronuclei at the zygote stages and thus select against triploids, parthenotes or unfertilized embryos an excellent method for selecting human embryos with high implantation potential (Lundqvist et al., 2001). Besides that, a polarized distribution of the pronuclei during pronuclear alignment is related to chromosomally normal embryos in humans (Coskun et al., 2003).

Studies show that the presence of serum in the culture medium can induce accumulation of cytoplasmic lipid droplets in bovine embryos. These fluctuations of cytoplasmic lipid droplets make darker embryos and lesser cryotolerant. The Sudan Black staining method has been vastly used for identifying embryos with increased numbers of lipid droplets (Abe et al., 2002; Sudano et al., 2011). Serum also affects the duration from maximal compaction to blastulation, shortening $12 \mathrm{~h}$ in comparison to IVD embryos. This short compaction period and early blastulation in embryos coincided with perturbed allocation of cells to the inner cell mass and trophectoderm and is caused by decreased expression of transcripts that are involved in the construction of tight junctions, all this together decreased cryosurvival of the subsequently formed blastocysts (Van Soom et al., 1997; Miller et al., 2003).

Timing of blastocyst formation is a good marker for embryo quality as well early cavitating embryos are superior in comparison with the latter cavitating embryos in regard to total cell number, allocation of inner cell mass and trophectoderm cells, and cryosurvival (Mahmoudzadeh et al., 1995; Van Soom et al., 1997). Although, reliable morphological predictors at the blastocyst stage for competence after embryo transfer are still lacking. Nevertheless, there is a consensus by many research groups and commercial companies that the greatest results of pregnancy rates are generally achieved after the transfer of bovine day 7 expanded blastocysts regardless of whether they were fresh or cryopreserved (Hasler 2000; Xu et al., 2006; Block et al., 2009; Sanches et al., 2013; Munoz et al., 2014; Mogas, 2019).

Embryos suffer considerable morphofunctional damage when they are cryopreserved. The challenge during the process of vitrification/freezing followed by warming/thawing is enormous, which includes osmotic, thermic and mechanical stress. The extent of the cryopreservation injuries depends on factors such as the membrane permeability, size and shape of the cells, and quality and sensitivity of the blastomeres (Vajta and Kuwayama, 2006). In order to obtain greater cryosurvival results, therefore, it is sound to cryopreserve following transfer expanded blastocysts of extraordinary superior quality. No signs of degeneration in the morphological evaluation of embryos would be recommended (Hasler 2000; Xu et al., 2006; Block et al., 2009; Sanches et al., 2013; Munoz et al., 2014; Mogas, 2019).

\section{Embryo cellular competence}

The initial development of embryos in mammals has unique physiological characteristics and 
mechanisms of regulation. Modifications in the properties of cytoplasmic organelles, such as location, morphology and biochemical activity must occur to achieve high quality during development (Sirard et al., 2006; Mao et al., 2014).

Initially, mitochondria constitute the powerhouses of cells, responsible for energy to boost all cellular functions. This organelle has an important role in calcium homoeostasis, fatty acid oxidation and apoptosis (Lledo et al., 2018). The embryo only starts to replicate it at hatched blastocyst stage, so all stages before depends on the mitochondrias pre-existent in the oocyte (Spikings et al., 2006). Alterations in normal mitochondrial functions can lead to metabolic diseases affecting the preimplantation development (Van Blerkom, 2004; Schaefer et al., 2008). In the early cell division cycle, the embryo has a greater amount of mitochondrias in storage, which is diluted as the divisions progress. This is the reason for blastocysts have few copies per cell, considered the mechanism for high quality transmission by the bottle neck theory (Lee et al., 2012). Therefore, just only at the implantation period the embryo is capable of replicate mitochondrial DNA (mtDNA) (Thouas et al., 2005; St John et al., 2010).

The initial production of energy in the early stages of embryonic development occurs through aerobic and anaerobic respiration (Thouas et al., 2005; El Shourbagy et al., 2006; Spikings et al., 2007), and is critical in several species. Human (May-Panloup et al., 2005), murine (Liu et al., 2000; Thouas et al., 2004), bovine (Chiaratti et al., 2011), and porcine (Spikings et al., 2007) studies have shown that problems in mitochondrial function lead to reduced cleavage rates and aneuploidy occurrence. In addition, low production of ATP and decrease of mtDNA copies are related with poor quality embryos (Wai et al., 2010; Wakefield et al., 2011). Another important change is the remodelling of mitochondrial features, turning into a complex structure that includes development of cristae, denser matrix and elongated form. These transitions are crucial to change from glycolytic to aerobic metabolism (Schatten et al., 2014).

Response to exogenous stress is a crucial part of cellular physiology. The main mechanism to start the cellular stress response pathway is located in the endoplasmic reticulum (ER). This organelle is responsible for secreting various proteins involved in several biological processes and its quality control is responsible for detecting failures to maintain the functioning of the cells which include processes of cell division, homeostasis, and differentiation (Latham, 2015). Disturbance in the endoplasmic reticulum stress signalling, especially in the GRP78 / BiP protein, leads to problems in the pre-implantation period, failure in blastocyst hatching and defects in cell division and apoptosis of the inner cell mass (Luo et al., 2006).

Another cellular component is the structure of the cytoskeleton, essential in diverse cellular functions and embryonic development. The cytoskeleton is composed of microfilaments, intermediate filaments and microtubules. Damage to the cytoskeleton adversely affects cell viability and can cause disruption in development and survival, given the support for intracellular content to be organized (Mao et al., 2014). In Damiman et al (2013) study, the comparison between slow-freezing and non-cryopreserved embryos showed a decrease of tubulin, actin and nucleus structures in each stage compared in mouse, indicating that may the vitrification technique would cause less damage on cytoskeleton (Dasiman et al., 2013). The IVPE can also modify the cytoskeleton leading, in some cases, to aberrant actin organization that is responsible for decreased development in IVP embryos (Mao et al., 2014). It was described in the literature that the supplementation of melatonin, a cytoskeletal modulator, reverse the damage in actin organization related genes, such as Rho/Rac guanine nucleotide exchange factor 2 (Arhgef2), BCL2 apoptosis regulator (Bcl2), coronin 2B (Coro2b), filamin C (Flnc), and palladin cytoskeletal associated protein (Palld), providing a target to optimize existing in vitro production systems (Tan et al., 2015).

Membrane damage and DNA fragmentation are the most commonly injury caused by cryopreservation (Sudano et al., 2012). Both injuries are associated with the reduction in the total cell number after cryopreservation and also the disturbance in the proportion of inner cell mass (ICM) / trophectoderm (TE) cells ratio (Sudano et al., 2012; Gomez, 2009). The proper ICM/TE ratio and cells number is crucial for embryo development and pregnancy establishment (Van Soom et al., 1996; Leese et al., 1998). These cryoinjuries can severe reduce embryo survival and the ability for the pregnancy success.

Many ultrastructural damages are commonly related to embryo cryopreservation, including: plasma membrane disruption, abnormal mitochondrial cristae, matrix swelling of the endoplasmic reticulum, poorly developed desmosome, reduced number of microvilli, disintegrations of cell adhesion among TE cells, and increase incidence of cell death (Overstrom et al., 1993; Vajta et al., 1997; Fair et al., 2001).

Nevertheless, many of this cryoinjury can be avoided by a proper cryopreservation methodology and rigorous application of technique assuring correct time of exposure and temperature of the cryopreservation steps. Additionally, cryopreserve exceptional quality embryos tend to reduce cryoinjuries, and clear signs of regeneration and reorganization of embryonic structures are expected after warming/thawing and re-culture, including re-establishment of tight-junctions between TE cells and the return of normal mitochondrial morphology (Vajta et al., 1997).

\section{Embryo molecular competence}

Beyond morphological analyses, other techniques that reflect the functional and physiological state of the embryo have been proposed, such as the molecular analysis. Basically we can evaluate the embryos based into three groups of different stages of cellular functioning: (1) production of transcripts and proteins from specific genes of cellular products, (2) final products of cellular processes (metabolites) and (3) 
gene expression regulatory transcripts, the so-called small non-coding RNAs (ncRNAs), such as: interference RNA (siRNA), micro RNAs (miRNA) and antisense RNA (Phillips, 2008; Rodgaard et al., 2015). The present review focused on mRNA transcripts evaluation and discussed briefly other molecular aspects.

Morphological embryonic development events as first cleavages, compaction and blastulation are accompanied by a loss of pluripotency and formation of lineages of trophectoderm and inner cell mass to further development of the three primary germ layers: endoderm, mesoderm and ectoderm (Stephenson et al., 2012; Schrode et al., 2013). During this period, not only embryo morphology undergoes modifications, changes in the transcripts levels for genes associated with early embryo development dynamic occur. Transcription factors required for maintenance of pluripotency, such as POU class 5 homeobox 1 (POU5F1/Oct4), SRY-box transcription factor 2 (SOX2) and Nanog homeobox (NANOG), expressed strictly in ICM cells, mediated by the action of the caudal type homeobox 2 (CDX2) gene product expressed on trophectoderm cells (Chambers et al., 2003; Ralston and Rossant, 2008) have been widely described.

During the embryo pre-implantation period, there is a massive degradation of the maternal RNA/proteins stored inside the oocyte and the gradual activation of the embryonic genome. Studies that inhibit RNA polymerase II have demonstrated that the time of the embryonic genome activation (EGA) is related to the rate of embryonic development. In bovine, EGA occurs between 8-16 cells and is associated with early differentiation, embryo implantation success, and fetal development. However, the regulation of the gene expression of bovine embryos remains an unresolved biological issue (Misirlioglu et al., 2006; Graf et al., 2014).

A correlation between EGA with increased abundances of mature forms of miR30a and miR-21, and the primary form of miR-130a from 1-cell to 8-cell zygotes have been described (Mondou et al., 2012). Tripurani et al (2013) pointed to another miRNA with increased expression in 2- to 8-cell embryos, miR-212, possibly a suppressor of the maternal factor in the germ line at the transition of transcripts and maternal proteins to those of the embryo, called the maternal-embryonic transition. Although specific mechanisms of EGA are poorly defined, some factors involved such as maternal cyclin A2 (CCNA2), retinoblastoma protein (RB1), catalytic subunit of the SWI/SNF-related chromatin remodelling complex (BRG1), and the SRY-box transcription factor 2 (SOX2) have recently been suggested in an EGA model in mice (Tripurani et al., 2013). Embryos that do not properly undergo genome activation fail in the further development.

It has already been described that biopsies derived from IVP blastocysts that resulted in calf delivery were enriched with transcripts necessary for implantation (cytochrome c oxidase subunit II, COX2 and caudal type homeobox 2, CDX2), carbohydrate metabolism (arachidonate 15-lipoxygenase, ALOX15), growth factor (bone morphogenetic protein 15, BMP15), signal transduction by plasminogen activator urokinase (plasminogen activator urokinase, $P L A U$ ) and placenta (placenta-specific 8, PLAC8). Transcripts involved in protein phosphorylation (keratin 8, KRT8), plasma membrane (occludin, OCLN) and glucose metabolism (phosphoglycerate kinase 1, PGK1 and aldo-keto reductase family 1 member $\mathrm{B} 1, A K R 1 B 1$ ) were enriched in reabsorbed embryos. Embryos that did not resulted in pregnancy presented enriched transcripts involved with inflammatory cytokines (tumor necrosis factor, TNF), amino acid binding protein (eukaryotic translation elongation factor 1 alpha 1 , EEF1A1), transcription factors (msh bomeobox 1, MSX1, and PTTG1 regulator of sister chromatid separation securing, PTTG1), glucose metabolism (phosphoglycerate kinase 1, PGK1 and aldo-keto reductase family 1 member $\mathrm{B} 1, A K R 1 B 1$ ), and implantation inhibitor (CD9 molecule, CD9) (ElSayed et al., 2006).

Despite great improvement of the information availability of embryo competence, this knowledge was not enough to avoid pregnancy loss observed in all mammalian species, in which cause serious issues such as reproductive wastage in farm animals. It is generally expected pregnancy loss in cattle in $40 \%$ of the cases between day 8 and 18 (Diskin and Sreenan, 1980). This embryo mortality is caused by a series of events that includes intrinsic embryo's defects, unsatisfactory maternal environment and failure to synchronization between the cow and embryo.

Ghanem et al. (2011) identified 41 and 43 differently expressed genes between IVD blastocysts which resulted in no pregnancy vs. calf delivery and pregnancy loss vs. calf delivery, respectively. In general, genes related to placental development and maternal-embryo interaction (placenta-specific 8, PLAC8) were upregulated in embryos that had pregnancy to term. On the other hand, embryo's biopsies that did not end in successful pregnancy presented enriched transcripts related to mitochondrial transcripts (Bos taurus isolate FL405 mitochondrion, Fl405) and stress genes (heat shock protein family D (Hsp60) member 1, HSPD1). However, both biopsies presented similar gene expression related to preimplantation development of embryo.

Another study also evaluating the molecular signatures of IVD embryo biopsies which resulted in no pregnancy and calf delivery identified 70 differently expressed genes: 32 transcripts levels were upregulated in the biopsies from calf delivery-derived embryos, such as sperm associated antigen 17 (SPAG17/PF6), ubiquitin conjugating enzyme E2 D3 (UBE2D3P), deafness autosomal recessive 31 (DFNB31), Sadenosylmethionine decarboxylase 1 (AMD1), dystrobrevin binding protein 1 (DTNBP1), and adpribosylation factor-like 8B (ARL8B); whereas 38 transcripts levels including RING1 and YY1 binding protein (RYBP), ring finger protein 34 (RNF34), karyopherin alpha 4 (KPNA4), and WD repeat domain 13 (WDR13) were increased in the biopsies of the no pregnancy-derived embryos indicating that the embryos are molecularly distinguishable (Salilew-Wondim et al., 
2010). The biopsy transcriptional profiles from cryopreserved blastocysts that resulted in calf delivery, no pregnancy, and pregnancy loss are still lacking.

Our group have recently evaluated the transcriptional profiles of IVP bovine embryos with high and low post-cryopreservation survival. Blastocysts with high cryosurvival were enriched in 27 genes associated with the following top five biological processes: a) predicted to be activated: organismal survival, cell death and survival, cellular growth and proliferation; and b) predicted to be inhibited: cellular movement and cell-tocell signalling (data not published).

A favourable transcriptional profile for pregnancy establishment and maintenance, therefore, could be used as a marker of embryo competence. In addition, each gene and/or genes involved pathway should be studied in order to design strategies applied to the in vitro embryo production system to improve embryo quality, cryosurvival and embryo-derived pregnancy.
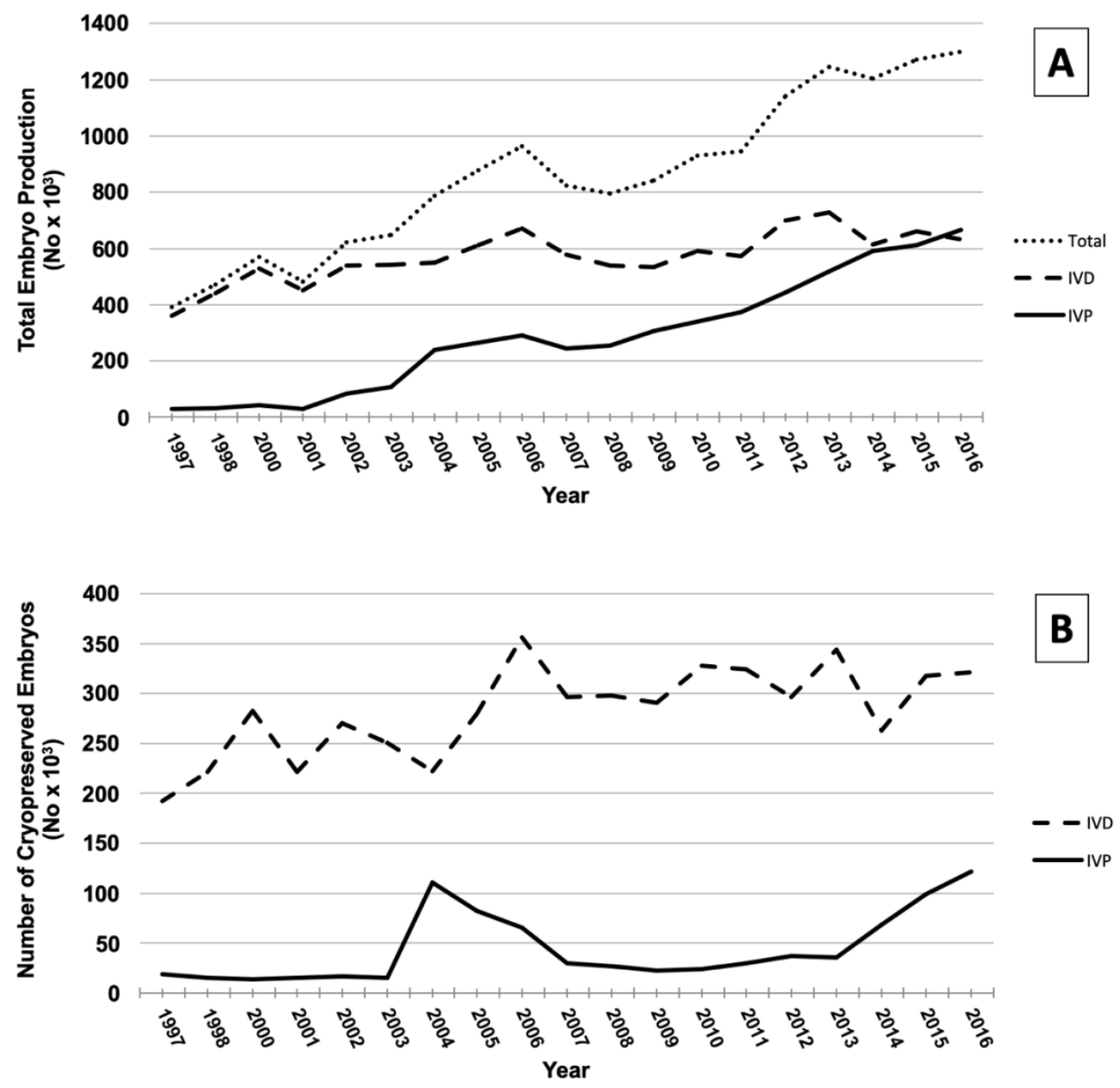

Figure 1. Total number, in vivo derived (IVD) and in vitro produced (IVP) bovine embryos in the world over the last 20 years (A). Number of cryopreserved IVD and IVP bovine embryos in the world in the last 20 years (B). Source: Data retrieval committee, International embryo technology society - IETS (https:/www.iets.org/comm_data.asp? autotry=true\&ULnotkn=true, accessed June 2019; and Perry, 2017).

\section{Determinant effects of embryo competence and cryosurvival}

Early embryo development period is complex, conserved, and well-orchestrated process involving dynamic molecular and structures changes. Embryos must undergo important events, such as fertilization, cleavage, epigenetic reprogramming, compaction, differentiation, and blastulation, for proper development and pregnancy establishment (Sudano et al., 2016a; Jiang et al., 2014).
Several factors can disrupt competence during this period and result in variations of the embryo phenotypes, including genotype and environmental effects. Because of this reason, a rigorous quality control should be used to perform all the steps involved in the IVPE in order to mimic as much as possible the in vivo environment conditions and reduce possible genotype effect. A putative model addressing cellular and molecular events required for acquisition of embryonic developmental competence and cryosurvival is presented at Figure 2. 


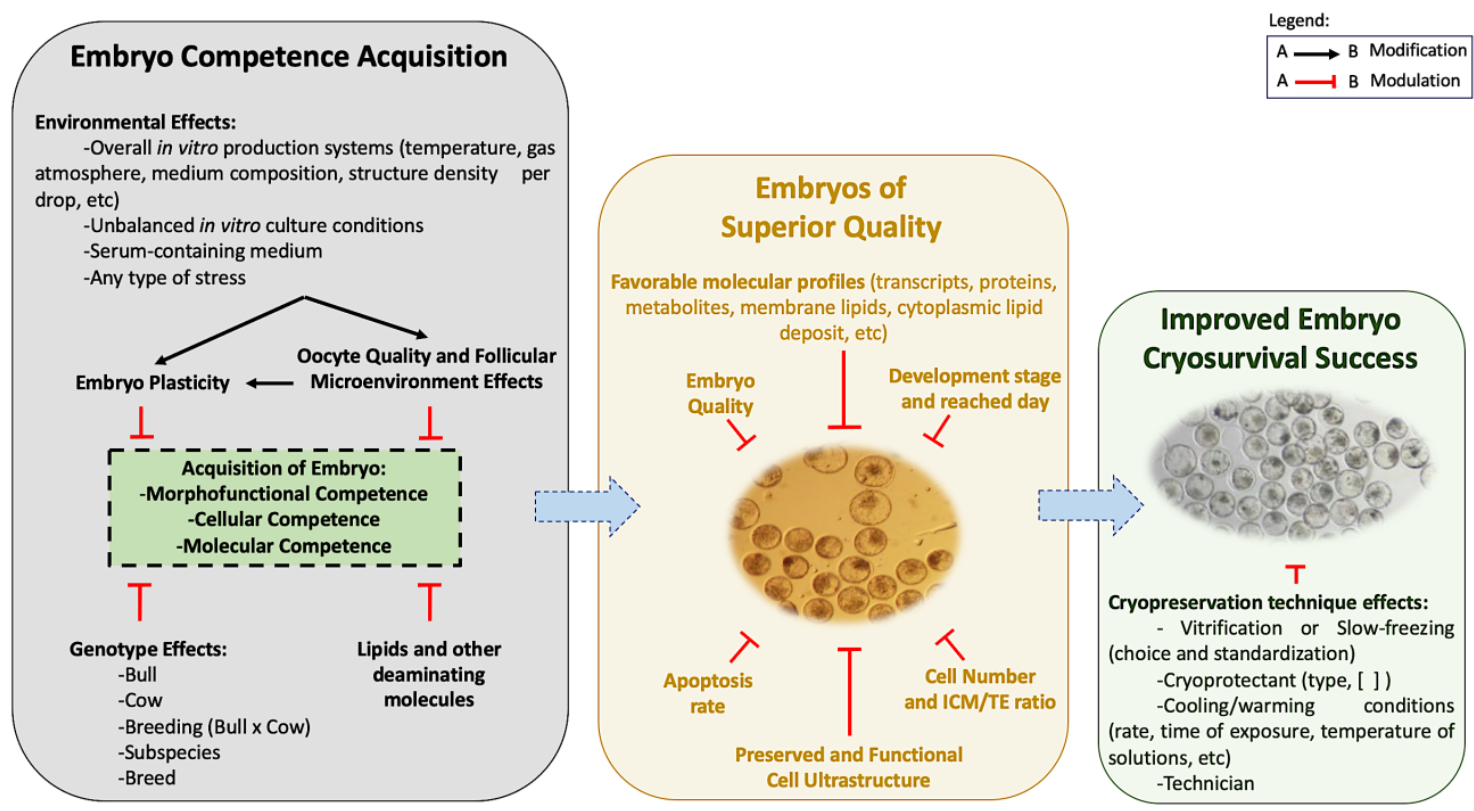

Figure 2. Cellular and molecular events required for embryonic developmental competence acquisition and its impact on cryosurvival. Interconnected steps (blue dashed arrows, from the left to the right) to in vitro produce an embryo of superior quality and improved embryo cryosurvival success. Overall environmental and genetic effects on embryo competence acquisition (Black Box). Determinant variables associated with the in vitro production of superior embryo quality (Gold Box, in detail fresh IVP blastocysts with great quality). Successful resumption of development after cryopreservation and cryopreservation technique effects (Green Box, in detail re-expanded IVP blastocysts after warming). All Box events (Black, Gold and Green) impact embryo cryosurvival.

\section{Genotype effect}

It is well documented in the literature the great variation in the developmental competence of IVP bovine embryos according to the sire (Brackett and Zuelke, 1993; Galli and Lazzari, 1996). Variables like cleavage and blastocyst production rates of a specific bull and/or semen batch (with unknow IVF results) are generally previously evaluated in vitro before the vastly use of this semen in the IVPE routine. Nevertheless, there are considerable variations of pregnancy rates observed after the embryo transfer according to the sire used for both fresh and cryopreserved embryos.

Our group recently evaluated the sire effect in the pregnancy rates following the transfer of fresh $(\mathrm{N}=$ $40,200)$ or cryopreserved $(N=9,858)$ IVP embryos. Pregnancy rates varying among 28.3 to $52.5 \%$ (for fresh) and 7.7 to $61.6 \%$ (for cryopreserved) were recorded after transfer IVP embryos derived from different bulls. We also have observed a variation according the cow, breeding, subspecies, and breed on pregnancy rates (Sudano et al., 2019). However, despite great amount of the variation was attributed to the genotype effect in this evaluation, it is also important to considerate the environmental effect in the determination of the reason of variation.

Variations in the membrane lipid profiles of phosphatidylcholine and sphingomyelin between Bos taurus indicus (Nellore) and Bos taurus taurus (Simmental) embryos and its impact on the embryo's cryosurvival have already been reported (Sudano et al., 2012; 2013a). After vitrification the evaluation of the percentage of structures hatching revealed results superior to B. taurus taurus (34.6\%) compared to $B$. taurus indicus (20.2\%) embryos (Sudano et al., 2013a). Arreseigor et al. (1998) also showed this difference between subspecies in the pregnancy rate. It seems that factors including the phospholipid cell membrane composition are associated with the determination of the physicochemical properties such as fluidity, permeability and thermal phase behavior, which are determinants for cryotolerance (Van Meer et al., 2008).

\section{Oocyte quality and the follicular environment effects}

The production of competent oocytes is dependent on complete nuclear and cytoplasmic maturation. The oocyte during its development undergoes rearrangements that make it capable of supporting fertilization and early embryonic development. During the nuclear maturation process, oocyte chromosomes go through diplotene of prophase I to metaphase II of meiosis. Among the main changes in cytoplasmic maturation are carbohydrate and lipid metabolism, mitochondrial function and location, reduction of oxygen radicals, epigenetic reprogramming, bidirectional communication between the cumulus-oocyte complexes (COC) and its secretion of growth factors (Brevini Gandolfi and Gandolfi, 2001). All this events are crucial for a proper oocyte competence acquisition.

In the commercial IVPE programs, the ultrasound-guided follicular aspiration (OPU) is routinely used for oocyte recovery, this biotechnology allows access a large number of female gametes in 
mono-ovulatory species favoring the multiplication of animals with exponentially genetic merit (Nagai et al., 2015; Nagano, 2019). Investigations on the influence of the follicle microenvironment and size in the establishment of competent embryos have been conducted (Annes et al., 2018; Labrecque et al., 2016; Lonergan et al., 2016).

There is considerable effect of follicle conditions in the oocyte and embryo competence. Oocyte origin is the main factor affecting blastocyst yield (Rizos et al., 2002). Any type of stress conditions that oocytes face can potentially disrupts embryo development. Differences in the morphology (Nagai et al., 2015; Nagano, 2019), lipid composition, transcriptome, and embryo development (Labrecque et al., 2016; Annes et al., 2018) had already been described in the oocytes recovery from different follicle sizes. The bovine oocytes used for IVPE are recovered from follicles with 2 to $8 \mathrm{~mm}$ of diameter, before follicle divergence. Generally, oocytes recovered from large follicles $(>6 \mathrm{~mm}$ ) present a greater potential of reaching blastocysts compared to oocytes recovered from follicles of 2 to $6 \mathrm{~mm}$ (Rizos et al., 2002; Fair, 2003; Labrecque et al., 2016; Annes et al, 2018).

Despite embryo culture conditions is crucial for embryo quality and cryosurvival determination (Rizos et al., 2002), blastocysts that originate from oocytes matured in vitro result in lower rates of gestation compared to their in vivo counterparts (Peterson and Lee, 2003). Additionally, we recently identified a relationship between the cytoplasmic lipid content of oocytes and the lipid deposit of expanded blastocysts (Annes et al., 2018), i.e., oocytes derived from large follicles and containing greater amount of lipid droplets, originated day 7 expanded blastocysts, after IVPE, with increased lipid deposit. An experiment evaluating the cryosurvival of these blastocysts is still lacking, however, it is fair to speculate that this increased lipid deposit negatively impact embryo cryosurvival (Abe et al., 2002).

This results collaborate in the selection of follicles/oocytes of greater potential, since key events for embryonic development are dependent of oocyte status (Fair, 2010). A properly embryo developmental competence, therefore, could be increased in an oocyte focused manner.

\section{In vitro production conditions effects}

It is commonly accepted that IVP embryos have a reduced competence compared with the in vivo counterparts. In vitro production of embryos is a threestep procedure involving oocyte maturation, fertilization, and in vitro culture of embryos. The in vitro environment directly influences the embryonic phenotypes and results. It is very important, therefore, to mimic the conditions found in vivo in order to allow all events inherent to the early embryonic development occur (for review, see Sudano et al., 2012; 2013a; 2013b).
Since the first notice of a calf delivery from a completely IVP embryo (in vitro maturation, fertilization and culture; Lu et al., 1987) the in vitro production systems still have challenging outcomes. Despite 80 to $90 \%$ of oocytes submitted to in vitro maturation have the germinal vesicle breaks down from prophase I to metaphase II, and $80 \%$ cleave after fertilization, only 20 to $40 \%$ of the oocytes develop to the blastocyst stage, and $50 \%$ of transferred IVP blastocysts establish pregnancy, i.e., just only 10 to 20 $\%$ of the recovered oocytes submitted to in vitro production will result in pregnancy (Lonergan et al., 2016, 2006; Rizos et al., 2008; Wrenzycki and Stinshoff, 2013; Sudano et al., 2019).

In vivo, oocyte maturation occurs during follicle development, a period that oocytes produce and storage mRNAs and protein molecules necessary to supply the first embryonic activities (Brevini Gandolfi and Gandolfi, 2001). In vitro, the maturation medium and in vitro process are responsible to provide conditions to the oocytes undergo nuclear (reach metaphase II of meiosis), cytoplasmic (re-distribution of organelles such as the mitochondria and the cortical granules) and molecular (accumulation of specific molecules, largely unidentified, which prepare the oocyte for post-fertilization events) maturation (Sirard et al., 2006). However, the in vitro maturation conditions are still not so much efficient. It was reported that blastocyst production from oocytes matured in vitro is lower than in vivo (39.2\% vs. $58.2 \%$, respectively; Rizos et al., 2002). Even if different supplements like grown factors and hormones were supplemented during IVM, the blastocyst development rate was not higher compared with the serum-supplemented medium highlighting the importance of the initial status of the oocyte (Ward et al., 2002; Hoelker et al., 2014).

In this context, there are some investigative approach studies describing a greater gene expression pattern correspondent to cytoplasmic maturation involved genes in oocytes with higher blastocyst production (Räty et al., 2011) and also a greater expression for apoptosis activating related genes to noncompetent structures (Warzych et al., 2007). This kind of works and a better understanding of in vivo oocyte maturation could improve the development of the maturation medium that produces viable embryos (Wrenzycki and Stinshoff, 2013).

In the literature, there is a consensus that improvements in oocyte quality is crucial for the proportion of oocytes developing to blastocysts stage, whereas the post-fertilization environment period is the major aspect determining the blastocyst quality and competence, including post-cryopreservation survival (Rizos et al., 2002; Lonergan et al., 2003; Hoelker et al., 2014).

In vivo, fertilization and early embryonic development take place at the oviduct due to the ability of this microenvironment to support embryogenesis, providing nutrients, growth factors, antioxidants, sex 
hormones, proteases, and other regulatory molecules of gametes and embryos. Furthermore, the cellular structure of this reproductive organ allows the transport of embryos to the uterus (Li and Winuthayanon, 2017; Rizos et al., 2008, 2002). Mimic in vivo environment is very difficult and somehow we generally failed in this task. Unbalanced in vitro culture conditions itself impacts directly embryo competence, since it has a significant effect on the cellular metabolism (D'Souza et al., 2018; Khurana and Niemann, 2000; Rizos et al., 2002) quality and quantity of lipids (Sudano et al., 2016a), gene expression patterns (Lonergan et al., 2006), and on modifications in epigenetic markers, which can continue after birth (Ramos-Ibeas et al., 2019).

However, despite the great diversity of culture media and systems available and used for IVPE with research purpose and commercially, they generally are associated with a relative good developmental potential which sheds light to the embryo plasticity, i.e., the capacity to fetch survival and adapt to adverse conditions even in an environment that do not supply or exacerbate their physiological needs (Khurana and Niemann, 2000; Lonergan et al., 2006). For example, the capacity of switching energy consumption source according nutrient availability. In mice, this plasticity was represented by the significant increase of the consumption of pyruvate, due to lack of glucose in the used medium (Gardner and Leese, 1988).

At molecular level, the great plasticity and tolerance to distinct culture conditions/systems including temperature, gas atmosphere, medium composition, embryo density per drop, and many other situations, are associated with an exacerbate gene expression pattern on IVP embryos compared with the in vivo counterparts (Corcoran et al., 2006; Côté et al., 2011; Sudano et al., 2013a).

However, this embryo plasticity can cause some severe damage to its competence and offspring; e.g. the large offspring syndrome in cattle (McEvoy et al., 2000; Rizos et al., 2008) and the overweighting newborns in humans ( $\mathrm{Li}$ and Winuthayanon, 2017). In bovines, this anomaly is associated with a protein source used in the culture media, the fetal calf serum (FCS), characterized by abnormal fetal and placental size, increased myogenesis, dystocia, abnormal neonatal lung activity, and increased post-neonatal mortality (McEvoy et al., 2000; Walker et al., 1996). In addition, as previously cited in this review, the FCS supplementation was also associated with increased cytoplasmic lipid deposit and reduced cryosurvival of the embryos (Abe et al., 2002; Sudano., 2011). In a previous work of our group, the cytoplasmic lipid droplets fluctuation observed on IVP embryos was closed related with FCS concentration supplemented to the culture media (Sudano et al., 2011) and with the mRNA levels for ACSL3 (Sudano et al. 2016a).

Taking all these studies together, culture conditions dramatically affect embryo developmental potential, quality, and further ability to survive after cryopreservation, and establish and maintain pregnancy. Despite many knowledge of the in vitro production systems have been produced over the past decades, efficiency improvements in the biotechnology process of the bovine IVPE is still needed in order to increase blastocyst yield of an exceptional quality.

\section{Lipids and other determining molecules for embryo competence}

The morphological transitions performed by embryos during the early development until implantation are accompanied by changes in the substrate requirements due to the embryo metabolism demand during this period. In vivo, at the reproductive tract, where embryo development takes place, sources of amino acids, proteins, lactate, pyruvate, glucose, antioxidants, ions, growth factors, hormones, and lipids are dynamically available with variations in concentration according to species, estrous cycle period and location (Di Paolo and De Camilli, 2006).

The measurement of embryonic metabolism can be used as an important tool in the analysis of molecular and cellular competence (Thompson et al., 2016). Hamatani et al. (2004) described two different physiological profiles of blastocysts (dormancy and activation) according to the global expression of genes involved in cell cycle control, cell signaling, and energy metabolism. In a total of 18 genes associated with metabolism, 13 were expressed in blastocysts on activation and 5 in blastocysts on dormancy. These metabolism variations contributed to the further hypothesis of "quiet embryos", which describes the metabolic efficiency of competent embryos with the lower need of substrate for development as a result of a lower percentage of cell damage based in the comparison of IVD and IVP embryos (Leese et al., 2008, 2007).

When analyzing the energy metabolism during early embryonic development, energy consumption is relatively low until pre-compaction stage and the main source of ATP is derived from pyruvate through oxidative phosphorylation, whereas with blastocyst formation and cavitation process a significant increase on energy demand and consumption of glucose, pyruvate and oxygen are expected. Additionally, after formation of the blastocyst, other sources of energy are required in greater proportion, including: glucose, amino acids and lipids (D’Souza et al., 2018; Hu and Yu, 2017).

Because of the various formulations of medium used by IVF laboratories, the understanding of metabolic spent during IVPE helps in directing compositions that structure viable embryos to the establishment of pregnancy (Thompson et al., 2016). Recent studies showed a higher energetic requirement of pyruvate and lactate, during culture, for noncompetent embryos (D'Souza et al., 2018). The influence of the culture medium on the embryonic 
development and the production of healthy animals is already well established, so research that identifies the potential of energy supplements used in the bovine IVPE prevents the multiplication of inappropriate phenotypes (De Souza et al., 2015).

Additionally, lipids are an important source of ATP for cell development and actively participates in embryonic metabolic pathways ( $\mathrm{Hu}$ and $\mathrm{Yu}, 2017)$. Lipids are responsible for the cross-talk between embryo, oviduct and uterus. This event is necessary in the synchronization of molecular and cellular events during the pregnancy establishment.

Studies demonstrated the lipid importance in signaling and coordination of biological events by mediating lipids such as phosphatidylinositols, sphingolipids, and eicosanoids (Di Paolo and De Camilli, 2006; Wang and Dey, 2005). Lipids are essential cellular biomolecules for plasma membrane and membranes of several organelles (Di Paolo and De Camilli, 2006). In bovine embryos, a stage-specific dynamic lipid fluctuation was observed during early embryo development (Sudano et al., 2016a). In addition, our group identified an increase in the mRNA levels for ELOVL5 and ELOVL6 (two transcripts of the ELOVLs family, responsible for fatty acids elongation) at the morula stage preceding an increase in membrane phospholipids containing elongated saturated, monosaturated and polysaturated fatty acids (16, 18 and 20 carbons) at the blastocyst stage (Sudano et al., 2016a).

Cells can synthesize simple fatty acids due to their biological functions. In this sense, lipid elongation facilitates the formation of complex biomolecules for specific activities (Guillou et al., 2010). We have recently observed the involvement of the ELOVL5 in the lipid metabolism of IVP embryos by regulating the cytoplasmic lipid deposit and the abundance of phosphatidylcholines, phosphatidylethanolamines and triacylglycerol (data not published).

All these findings demonstrate the importance of understanding the mechanisms involved in energy metabolism and embryo lipids composition in order to optimize in vitro culture conditions to allow the production of embryos with superior quality and greater cryosurvival.

\section{Embryo cryopreservation}

Embryo cryopreservation is a nitrogen $\left(\mathrm{N}_{2}\right)$ based conservation biotechnology that aims to maintain the cells in quiescent state, prolong the viability for long periods of time and enable their use in a timely manner (Fig. 3 3). In the area of assisted reproduction, primordial germ cells, gametes and embryos can be cryopreserved. It is considered a strategy to overcome logistical problems associated with the transfer of a large number of fresh embryos and mainly for the expansion of the commercialization of embryos between countries (Sudano et al., 2013b). Among the advantages are the optimization of reproductive biotechnologies such as IVPE and transfer of embryos in order to preserve surplus embryos, conservation of the genetic material of endangered species, prevention of problems arising from the transport of live animals and adaptations of the calving season.

The first success report on the survival of embryos (mice) subjected to freezing/thawing was recorded by Whittingham et al. (1972). In the following years, the technique was also applied successfully in different species and embryo cryopreservation started to be applied commercially. In Brazil, the majority of the IVP embryos are still transferred fresh, but the percentage of frozen (33.7\%) follows a growth trend, and among the embryos produced in vivo, the slow freezing is the preferred option (62.1\% of the total) (Viana, 2018). The principle of cryopreservation consists of maximum removal of water from the interior of the cells before freezing, avoiding the formation of large ice crystals that cause cell damage, which allows the resumption of cellular metabolism after storage at low temperatures. For this reason, cryopreservation strategies are based on two main factors: cooling/warming rates and choice of suitable cryoprotectants (CPA) (Vajta and Kuwayama, 2006).

According to Mazur (1980) there is a correlation between the cooling rate and the appearance of cell lesions, i.e. as the freezing rate increases, the survival after thawing also increases, until an ideal maximum index is reached from which the higher freezing speed also leads to greater damage and lower embryo survival. In addition to the freezing rate curve, the use of CPA is essential to provide cellular protection against temperature drop. Although CPA are absolutely necessary and widely used in cryopreservation protocols, the mechanisms that confer protection of the biological material as well as the toxicity and cellular metabolism of these agents are not fully elucidated and addressed in the literature (Castro et al., 2011). For review all cryobiology principles involved on embryo cryopreservation, please see Sudano et al. (2016b).

It is known, at least partially, that the CPA protective effect comes from the reduction of the solidification point of the solutions and the ability on intermediating intracellular water removal/restauration. According to their ability to penetrate cell membranes, CPA are divided into two groups: permeable (e.g. glycerol, ethylene glycol and propylene glycol) and impermeable (e.g. sucrose, galactose, polyethylene glycol and polyvinylpyrrolidone). In addition, there are two major cryopreservation methodology currently applied for bovine embryos, slow freezing and vitrification. 

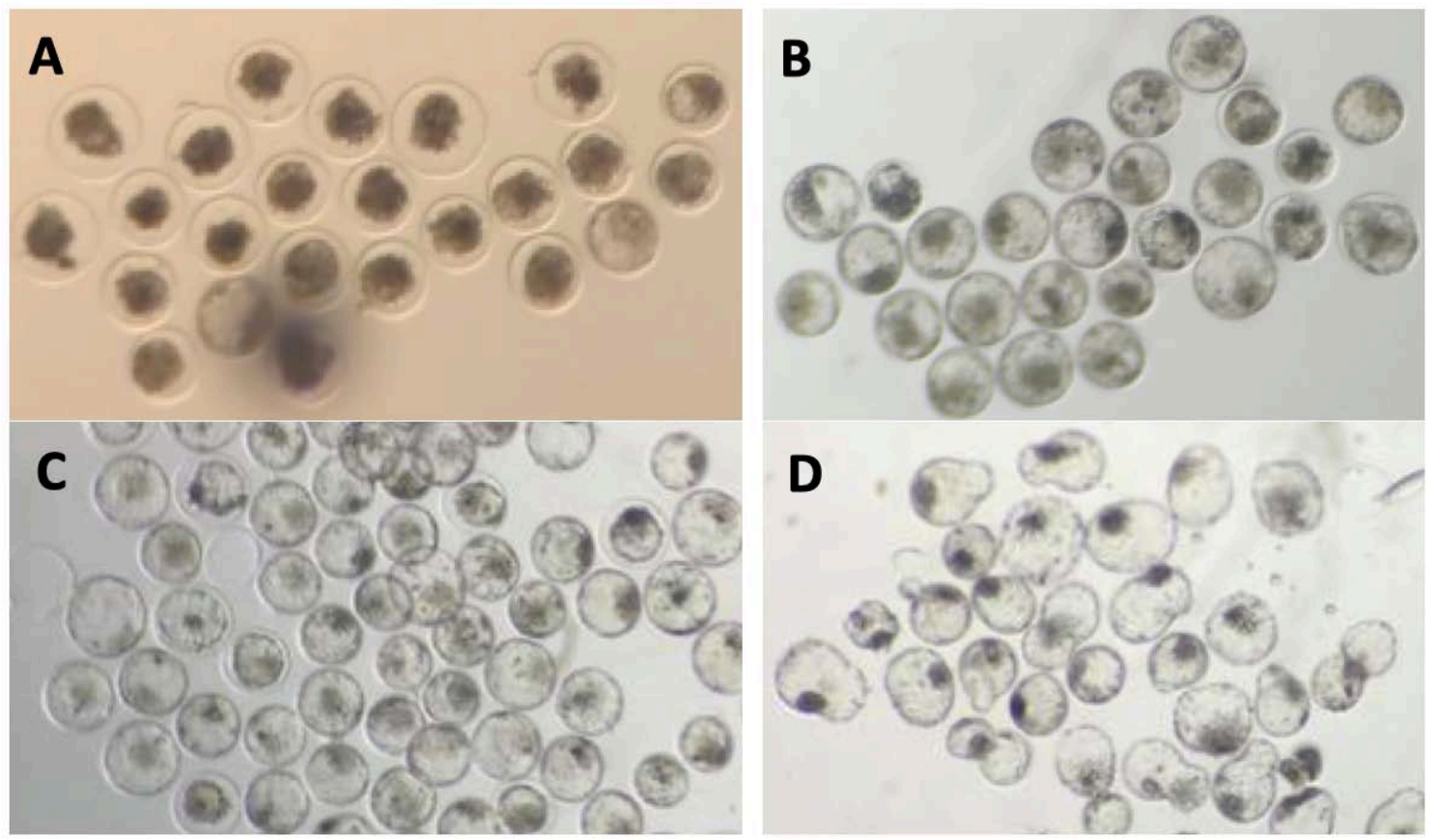

Figure 3. Vitrified in vitro produced bovine embryos immediately after warming (A), and following $6 \mathrm{~h}(\mathrm{~B})$ and $12 \mathrm{~h}$ (re-expanded and hatched blastocysts, respectively for C and D) of re-culture.

\section{Cryopreservation techniques}

Slow or classic freezing is one of the most widespread embryo cryopreservation techniques and is based on the use of glycerol or ethylene glycol as a CPA. The main advantage of this technique is the reduced cellular toxicity through the use of low concentrations of CPA, however, slow freezing still allows the formation of ice crystals that could lead to cellular damage. After a period of previous CPA exposure, the embryos are loaded in straws together with the CPA solution, which will be allocated in programmable freezing devices for cooling. The temperature drop is controlled by keeping a constant curve until the temperature reaches $-32^{\circ} \mathrm{C}$, when the straws containing the embryos are immersed in the liquid nitrogen. After thawing, the embryos must be placed in petri dishes where the CPA solution will be diluted by successive washes in dilution solutions. Alternatively, Leibo (1983) developed the One-Step method where dilution of the CPA still occurs in the straw after thawing, letting the transfer to recipients be without previous microscopic evaluation.

Although slow freezing is the most widely used method for the cryopreservation of IVD embryos, vitrification has emerged as an alternative to IVP embryos. When comparing the cryosurvival and pregnancy results of both procedures considering the production method, IVD embryos present similar results, for both slow freezing and vitrification, whereas IVP embryos present more satisfactory results with vitrification (Tab. 1 and 2). However, slow-freezing also can be a good option to cryopreserve IVP embryos, Sanches et al. (2016) reported similar pregnancy rates on Day 60 after the transfer of IVP embryo cryopreserved by slow-freezing $(34.7 \%, \mathrm{n}=311)$ or vitrification $(31.2 \%, \mathrm{n}=234)$.

Vitrification eradicates the damage caused by the formation of ice crystals during the cooling process. The cryopreservation medium undergoes a direct passage from the liquid state to a vitrified and amorphous state without the crystallization of the medium occurring, which it is possible due to the high viscosity of the cryopreservation medium and the high freezing rate $\left(>20.000^{\circ} \mathrm{C} / \mathrm{min}\right)$ by direct immersion in $\mathrm{N}_{2}$, from room temperature (Fahy et al., 1984). The technique is extremely fast and does not require the use of freezing devices; however, it requires more training and technical skills from the technician. Among the disadvantages are the difficulty of direct transfer and the need to use high concentrations of CPA that can cause cellular toxicity. As a result, several combinations with different CPA, concentrations and period of exposure have already been proposed. In order to ensure a rapid cooling rate, the use of the minimum volume of solution per sample is adopted in order to provide immediate contact with the $\mathrm{N}_{2}$. For this purpose, specific tools have been developed for packaging the embryos into microdrops, such as Open Pulled Straw (OPS) (Vajta et al., 1998), Cryoloop (Lane et al., 1999) and Cryotop (Kuwayama, 2007). More recently, a new automated vitrification methodology has been proposed (Arav et al., 2018), which may facilitate and optimize the standardization of the technique.

Despite great results were achieved with enhancements of the cryopreservation methodology over the last decades; an embryo-focused approach to improve cryosurvival has been recommended. 
Table 1. Post-cryopreservation survival of in vitro produced bovine embryos following slow-freezing and vitrification.

\begin{tabular}{|c|c|c|c|c|c|}
\hline \multirow{2}{*}{ Reference } & \multicolumn{2}{|c|}{ Slow-freezing (\%) } & \multicolumn{2}{|c|}{ Vitrification (\%) } & \multirow{2}{*}{ P-value } \\
\hline & Re-expansion & Hatching & Re-expansion & Hatching & \\
\hline Dinnyés et al., 1996 & $62.0^{\mathrm{a}}(\mathrm{n}=63)$ & $81.0^{\mathrm{A}}(\mathrm{n}=63)$ & $81.0^{b}(n=64)$ & $70.0^{\mathrm{A}}(\mathrm{n}=64)$ & $<$ or $>0.05$ \\
\hline O’Kearney-Flynn et al., 1998 & $58^{\mathrm{a}}(\mathrm{n}=73)$ & - & $86^{\mathrm{b}}(\mathrm{n}=64)$ & - & $<0.05$ \\
\hline Nedambale et al., 2004 & $40.0^{\mathrm{a}}(\mathrm{n}=297)$ & $22.0^{\mathrm{A}}(\mathrm{n}=297)$ & $64^{\mathrm{b}}(\mathrm{n}=297)$ & $54.0^{\mathrm{B}}(\mathrm{n}=297)$ & $<0.05$ \\
\hline Mucci et al., 2006 & $16.7^{\mathrm{a}}(\mathrm{n}=275)$ & $19.6^{A}(n=275)$ & $52.1^{\mathrm{b}}(\mathrm{n}=265)$ & $51.3^{B}(n=265)$ & $<0.05$ \\
\hline Barceló-Fimbres and Seidel, 2007 & $80.4(\mathrm{n}=360)$ & $19.1(n=360)$ & $77.7(\mathrm{n}=360)$ & $16.0(\mathrm{n}=360)$ & $>0.05$ \\
\hline Yu et al., 2010 & $46.9^{\mathrm{a}}(\mathrm{n}=155)$ & $24.7^{\mathrm{A}}(\mathrm{n}=155)$ & $58^{\mathrm{b}}(\mathrm{n}=153)$ & $36.2^{\mathrm{B}}(\mathrm{n}=153)$ & $<0.05$ \\
\hline Inaba et al., 2011 & $88.6(n=44)$ & $75.0^{\mathrm{A}}(\mathrm{n}=44)$ & $100(\mathrm{n}=44)$ & $93.2^{\mathrm{B}}(\mathrm{n}=44)$ & $<0.05$ \\
\hline
\end{tabular}

Re-expansion rate was evaluated 24h after thawing/warming and hatching/hatched rate was evaluate with 48 or $72 \mathrm{~h}$ after thawing/warming according the study methodology. Values without a common lowercase (comparisons between re-expansion rates) or uppercase (comparisons between hatching rates) letters differ $(\mathrm{P}<0.05)$.

Table 2. Post-cryopreservation survival of in vivo produced bovine embryos following slow-freezing and vitrification.

\begin{tabular}{lccc}
\hline \multirow{2}{*}{ Reference } & \multicolumn{2}{c}{ Pregnancy rate (\%) } & \multirow{2}{*}{ P-value } \\
\cline { 2 - 3 } & Slow-freezing & Vitrification & $>0.05$ \\
Massip et al., 1987 & $51.8(\mathrm{n}=27)$ & $39.1(\mathrm{n}=23)$ & 0.10 \\
van Wagtendonk-de Leeuw et al., 1995 & $59(\mathrm{n}=40)$ & $43(\mathrm{n}=34)$ & 0.79 \\
van Wagtendonk-de Leeuw et al., 1997 & $45.1(\mathrm{n}=335)$ & $44.5(\mathrm{n}=393)$ & $>0.05$ \\
Mattos et al., 2010 & $19.5(\mathrm{n}=79)$ & $17.8(\mathrm{n}=73)$ & $>0.05$ \\
Inaba et al., 2011 & $29.8(\mathrm{n}=102)$ & $36.6(\mathrm{n}=100)$ & $>0.05$ \\
\hline
\end{tabular}

\section{An embryo-focused approach to improve cryosurvival}

The effect of cryopreservation on mammalian embryos reduces survival rates, leading to considerable morphological and functional damage. However, the extent of cryoinjury is highly variable and dependent on the species, stage of development and origin of the embryo (produced in vivo or in vitro) at the time of cryopreservation (Dalcin and Lucci, 2010).

There is a consensus in the literature that IVP embryos present lesser cryoresistance compared with IVD embryos. Ultrastructural and biochemical characteristics such as increased lipid content, reduced intercellular junctions, fewer mitochondria and microvilli, larger perivitelline space and more cell debris are generally associated with the reduced cryosurvival of IVP embryos (Fair et al., 2001; Abe et al., 2002, Rizos et al. 2002). Additional variables associated with embryo cryosurvival are presented on Table 3. Thus, some strategies can be used to increase the cryotolerance of IVP embryos, such as culture under a low oxygen atmosphere system to minimize oxidative stress, addition of antioxidants to the culture medium, and the use of apoptosis inhibitors (Lin et al., 2018; Pero et al., 2018).

Table 3. Features positively or negatively associated with cryosurvival evaluated so far by our group.

\begin{tabular}{ll}
\hline Variables & Associated Cryosurvival \\
\hline Sire & Positively or Negatively \\
Genotype (Bos Taurus taurus vs. Bos Taurus indicus) & Positively or Negatively \\
Metabolic regulators and lipolytic molecule & Positively, Negatively or none \\
Embryo origin (IVP vs. IVD) & Positively or Negatively \\
Increased embryo quality & Positively \\
Increased fresh apoptosis rate & Negatively \\
Increased cytoplasmic lipid content & Negatively or positively \\
Membrane phospholipids profiles & Negatively or positively \\
Increased serum concentration & Negatively \\
\hline
\end{tabular}

As already mentioned, excessive lipid droplets accumulation of IVP embryos during development, especially of embryos cultured in serum-supplemented medium, is commonly associated with reduced cryosurvival and lower pregnancy rate (Rizos et al., 2008; Sudano et al., 2011). The exact mechanism for this increased lipid content on IVP embryos remains unknown. It seems that serum lipids could be absorbed by embryonic cells (Sata et al., 1999), altering the function of mitochondrial $\beta$-oxidation (Abe et al., 2002) and promoting the incorporation of saturated fatty acids and cholesterol in the cell membranes, which make them less permeable (Barceló-Fimbres and Seidel Jr, 2007). All these factors together also could explain the greater susceptibility of the IVP embryos to cryopreservation.

In fact, it is possible to produce embryos with a greater cryosurvival through manipulations of the culture medium. We have already demonstrated that only the reduction of the serum concentration in the developmental medium was capable of decrease the 
lipid content and increase embryo survival after cryopreservation (Sudano et al., 2011). Recently, our group participate in the development of a serum-free culture medium of IVP embryos that reach similar results of embryo quality and pregnancy rate compared with a serum-supplemented medium (data not published).

Alternatively, chemical substances that act as a delipidant or lipolytic agents, such as Forskolin (Sanches et al., 2013; Paschoal et al., 2014), L-carnitine (Held-Hoelker et al., 2017), and 10t,12c-CLA (Pereira et al., 2007) have been commonly adopted in the attempt to reduce the embryonic lipid content and improve cryosurvival. In addition, embryo delipidation after centrifugation and subsequent micromanipulation has already been proposed (Ushijima et al., 1999), however, considering this is an invasive and timeconsuming technique, this approach had become impracticable for large scale application and was limited for scientific purpose.

An additional strategy to improve cryosurvival of IVP embryos is the preincubation with growstimulating factors before cryopreservation. Beneficial effects of insulin-like growth factor 1 and leukaemia inhibitory factor were observed in the postcryopreservation survival of bovine blastocysts (Kocyigit and Cevik, 2015).

\section{Final considerations}

Embryo developmental competence and quality are crucial for cryosurvival and pregnancy success. Many variables can impair embryo competence and cryosurvival such as genotype, oocyte quality and follicular microenvironment, in vitro production conditions, and lipids and other determining molecules. A great quality control of all steps of IPVE and the use of exceptional quality embryos are recommended to improve and achieve homogenous results. A promising scenario for the next few years is expected for the use of the IVP embryos in the reproductive management of beef and dairy cattle. However, it is essential that further research efforts focus on improvements of the efficiency of producing a greater amount of embryos of superior quality, per oocytes recovered and round of in vitro fertilization, to be cryopreserved following transferred in order to reduce costs and justify the activity economically.

\section{Authors contributions}

TVM: Writing - original draft; JC: Writing original draft; RSV: Writing - original draft; MJS: Conceptualization, Funding acquisition, Writing review \& editing.

\section{Conflict of interest} declare.

The authors have no conflict of interest to

\section{Acknowledgments and Funding disclosure} statement

The present work was carried out with the support of CNPq, National Council of Scientific and
Technological Development - Brazil - grants (MJS) 446647/2014-4; (RSV) 165496/2017-7; and Coordenação de Aperfeiçoamento de Pessoal de Nível Superior Brasil (CAPES) - financial code 1 (TVM and JC).

\section{References}

Abe H, Yamashita S, Satoh T, Hoshi H. 2002. Accumulation of cytoplasmic lipid droplets in bovine embryos and cryotolerance of embryos developed in different culture systems using serum-free or serumcontaining media. Mol Reprod Dev, 61:57-66.

Annes K, Müller DB, Vilela JAP, Valente RS, Caetano DP, Cibin FWS, Milazzotto MP, Mesquita FS, Belaz KRA, Eberlin MN, Sudano MJ. 2018. Influence of follicle size on bovine oocyte lipid composition, follicular metabolic and stress markers, embryo development and blastocyst lipid content. Reprod Fertil Dev, 31:462-472.

Arav A, Natan Y, Kalo D, Komsky-Elbaz A, Roth Z, Levi-Setti PE, Leong M, Patrizio P. 2018. A new, simple, automatic vitrification device: preliminary results with murine and bovine oocytes and embryos. $J$ Assist Reprod Genet, 35:1161-1168.

Arreseigor CJ, Sisul A, Arreseigor AE, Stahringe RC. 1998. Effect of cryoprotectant, thawing method, embryo grade and breed on pregnancy rates of cryopreserved bovine embryos. Theriogenology, 49:160.

Báez F, Camargo A, Reyes AL, Márquez A, PaulaLopes F, Viñolese C. 2019. Time-dependent effects of heat shock on the zona pellucida ultrastructure and in vitro developmental competence of bovine oocytes. Reprod Biol, 19:195-203.

Barceló-Fimbres M, Seidel Jr G. 2007. Effects of fetal calf serum, phenazine ethosulfate and either glucose or fructose during in vitro culture of bovine embryos on embryonic development after cryopreservation. Mol Reprod Dev, 74:1395-1405.

Block J, Bonilla L, Hansen PJ. 2009. Effect of addition of hyaluronan to embryo culture medium on survival of bovine embryos in vitro following vitrification and establishment of pregnancy after transfer to recipients. Theriogenology, 71:1063-1071.

Bó G, Mapletoft RJ. 2013. Evaluation and classification of bovine embryos. Anim Reprod, 10:344-348.

Brackett BG, Zuelke KA. 1993. Analysis of factors involved in the in vitro production of bovine embryos. Theriogenology, 39:43-64.

Brevini Gandolfi TAL, Gandolfi F. 2001. The maternal legacy to the embryo: Cytoplasmic components and their effects on early development. Theriogenology, 55:1255-1276.

Castro S, de Andrade Carvalho A, Gomes da Silva CM, Rocha Faustino L, de Figueiredo JR, Ribeiro Rodrigues AP. 2011. Agentes crioprotetores intracelulares: características e utilização na criopreservação de tecido ovariano e oócitos. Acta Scientiae Veterinariae, 39:1-17.

Chambers I, Colby D, Robertson M, Nichols J, Lee S, Tweedie S, Smith A. 2003. Functional expression cloning of Nanog, a pluripotency sustaining factor in embryonic stem cells. Cell, 113:643-655.

Chiaratti MR, Ferreira CR, Perecin F, Meo SC, 
Sangalli JR, Mesquita LG, de Carvalho Balieiro JC, Smith LC, Garcia JM, Meirelles FV. 2011. Ooplastmediated developmental rescue of bovine oocytes exposed to ethidium bromide. Reprod Biomed Online, 22:172-183.

Corcoran D, Fair T, Park S, Rizos D, Patel OV, Smith GW, Coussens PM, Ireland JJ, Boland MP, Evans AC, Lonergan P. 2006. Suppressed expression of genes involved in transcription and translation in in vitro- compared with in vivo-cultured bovine embryos. Reproduction, 131:651-660.

Coskun S, Hellani A, Jaroudi K, Al-Mayman H, AlKabra M, Qeba M. 2003. Nucleolar precursor body distribution in pronuclei is correlated to chromosomal abnormalities in embryos. Reprod Biomed Online, 7:8690.

Côté I, Vigneault C, Laflamme I, Laquerre J, Fournier É, Gilbert I, Scantland S, Gagné, D, Blondin P, Robert C. 2011. Comprehensive crossproduction system assessment of the impact of in vitro microenvironment on the expression of messengers and long non-coding RNAs in the bovine blastocyst. Reproduction, 142:99-112.

D’Souza F, Uppangala S, Asampille G, Salian SR, Kalthur G, Talevi R, Atreya HS, Adiga SK. 2018. Spent embryo culture medium metabolites are related to the in vitro attachment ability of blastocysts. Sci Rep, 8:1-10.

Dalcin L, Lucci C. 2010. Criopreservação de embriões de animais de produção: princípios criobiológicos e estado atual. Rev Bras Reprod Anim, 34:149-159.

Dasiman R, Rahman NSA, Othman S, Mustafa MF, Mohd Yusoff NJ, Jusof WHW, Rajikin MH, Froemming GRA, Khan N. 2013. Cytoskeletal alterations in different developmental stages of in vivo cryopreserved preimplantation murine embryos. Med Sci Monit Basic Res, 19:258-266.

De Souza DK, Salles LP, Rosa E Silva A. 2015 Aspects of energetic substrate metabolism of in vitro and in vivo bovine embryos. Braz J Med Biol Res, 48:191-197.

Di Paolo G, De Camilli P. 2006. Phosphoinositides in cell regulation and membrane dynamics. Nature, 443:651-657

Dinnyés A, Carolan C, Lonergan P, Massip A, Mermillod P. 1996. Survival of frozen or vitrified bovine blastocysts produced in vitro in synthetic oviduct fluid. Theriogenology, 46:1425-1439.

Diskin MG, Sreenan JM. 1980. Fertilization and embryonic mortality rates in beef heifers after artificial insemination. J Reprod Fertil, 59:463-468.

El Shourbagy SH, Spikings EC, Freitas M, St John JC. 2006. Mitochondria directly influence fertilisation outcome in the pig. Reproduction, 131:233-245.

El-Sayed A, Hoelker M, Rings F, Salilew D, Jennen D, Tholen E, Sirard MA, Schellander K, Tesfaye D. 2006. Large-scale transcriptional analysis of bovine embryo biopsies in relation to pregnancy success after transfer to recipients. Physiol Genomics, 28:84-96.

Fahy GM, MacFarlane D, Angell C, Meryman $\mathbf{H}$. 1984. Vitrification as an approach to cryopreservation. Cryobiology, 21:407-426.
Fair T, Lonergan P, Dinnyes A, Cottell DC, Hyttel P, Ward FA, Boland MP. 2001. Ultrastructure of bovine blastocysts following cryopreservation: effect of method of blastocyst production. Mol Reprod Dev, 58:186-195.

Fair T. 2003. Follicular oocyte growth and acquisition of developmental competence. Anim Reprod Sci, 78:203-216.

Fair T. 2010. Mammalian oocyte development: checkpoints for competence. Reprod Fertil Dev, 22:13-20.

Galli C, Lazzari G. 1996. Practical aspects of IVM/IVF in cattle. Anim Reprod Sci, 42:371-379.

Gardner DK, Leese HJ. 1988. The role of glucose and pyruvate transport in regulating nutrient utilization by preimplantation mouse embryos. Development, 104:423-429.

Ghanem N, Salilew-Wondim D, Gad A, Tesfaye D, Phatsara C, Tholen E, Looft C, Schellander K, Hoelker M. 2011. Bovine blastocysts with developmental competence to term share similar expression of developmentally important genes although derived from different culture environments. Reproduction, 142:551-564.

Gomez E, Munoz M, Rodriguez A, Caamano JN, Facal N, Diez C. 2009. Vitrification of bovine blastocysts produced in vitro inflicts selective damage to the inner cell mass. Reprod Domest Anim, 44:194-199.

Graf A, Krebs S, Zakhartchenko V, Schwalb B, Blum H, Wolf E. 2014. Fine mapping of genome activation in bovine embryos by RNA sequencing. Proc Natl Acad Sci U S A, 111:4139-4144.

Guillou H, Zadravec D, Martin PGP, Jacobsson A. 2010. The key roles of elongases and desaturases in mammalian fatty acid metabolism: Insights from transgenic mice. Prog Lipid Res, 49:186-199.

Hamatani T, Daikoku T, Wang H, Matsumoto H, Carter MG, Ko MS, Dey SK. 2004. Global gene expression analysis identifies molecular pathways distinguishing blastocyst dormancy and activation. Proc Natl Acad Sci, 101:10326-31.

Hasler JF, Henderson WB, Hurtgen PJ, Jin ZQ, McCauley AD, Mower SA, Neely B, Shuey LS, Stokes JE, Trimmer SA. 1995. Production, freezing and transfer of bovine IVF embryos and subsequent calving results. Theriogenology, 43:141-152.

Hasler JF. 2000. In vitro culture of bovine embryos in Menezo's B2 medium with or without coculture and serum: the normalcy of pregnancies and calves resulting from transferred embryos. Anim Reprod Sci, 60-61:8191.

Held-Hoelker E, Klein S, Rings F, Salilew-Wondim $D$, Saeed-Zidane M, Neuhoff C, Tesfaye D, Schellander K, Hoelker M. 2017. Cryosurvival of in vitro produced bovine embryos supplemented with lCarnitine and concurrent reduction of fatty acids. Theriogenology, 96:145-152.

Hoelker M, Held E, Salilew-Wondim D, Schellander K, Tesfaye D. 2014. Molecular signatures of bovine embryo developmental competence. Reprod Fertil Dev, 26:22-36.

Hoelker M, Schmoll F, Schneider H, Rings F, Gilles M, Tesfaye D, Jennen D, Tholen E, Griese J, Schellander K. 2006. Bovine blastocyst diameter as a 
morphological tool to predict embryo cell counts, embryo sex, hatching ability and developmental characteristics after transfer to recipients. Reprod Fertil Dev, 18:551-557.

Holm P, Booth PJ, Callesen H. 2002. Kinetics of early in vitro development of bovine in vivo- and in vitroderived zygotes produced and/or cultured in chemically defined or serum-containing media. Reproduction, 123:553-565.

Hu K, Yu Y. 2017. Metabolite availability as a window to view the early embryo microenvironment in vivo. Mol Reprod Dev, 84:1027-1038.

Inaba $Y$, Aikawa $Y$, Hirai T, Hashiyada $Y$, Yamanouchi T, Misumi K, Ohtake M, Somfai T, Kobayashi S, Saito N, Matoba S, Konishi K, Imai K. 2011. In-straw cryoprotectant dilution for bovine embryos vitrified using Cryotop. J Reprod Dev, 57:437443

Jiang Z, Sun J, Dong H, Luo O, Zheng X, Obergfell C, Tang Y, Bi J, O'Neill R, Ruan Y, Chen J, Tian XC. 2014. Transcriptional profiles of bovine in vivo pre-implantation development. BMC Genomics, 15:115.

Khurana NK, Niemann H. 2000. Energy metabolism in preimplantation bovine embryos derived in vitro or in vivo. Biol Reprod, 62:847-856.

Kocyigit A, Cevik M. 2015. Effects of leukemia inhibitory factor and insulin-like growth factor-I on the cell allocation and cryotolerance of bovine blastocysts. Cryobiology, 71:64-69.

Kuwayama M. 2007. Highly efficient vitrification for cryopreservation of human oocytes and embryos: the Cryotop method. Theriogenology, 67:73-80.

Labrecque R, Fournier E, Sirard MA. 2016. Transcriptome analysis of bovine oocytes from distinct follicle sizes: Insights from correlation network analysis. Mol Reprod Dev, 83:558-569.

Lane M, Schoolcraft WB, Gardner DK, Phil D. 1999. Vitrification of mouse and human blastocysts using a novel cryoloop container-less technique. Fertility and sterility, 72:1073-1078.

Latham KE. 2015. Endoplasmic reticulum stress signaling in mammalian oocytes and embryos: Life in the balance. Int Rev Cell Mol Biol, 316:227-265.

Lee HS, Ma H, Juanes RC, Tachibana M, Sparman M, Woodward J, Ramsey C, Xu J, Kang EJ, Amato P, Mair G, Steinborn R, Mitalipov S. 2012. Rapid mitochondrial DNA segregation in primate preimplantation embryos precedes somatic and germline bottleneck. Cell Rep, 1:506-515.

Leese HJ, Baumann CG, Brison DR, McEvoy TG, Sturmey RG. 2008. Metabolism of the viable mammalian embryo: Quietness revisited. Mol Hum Reprod, 14:667-672.

Leese HJ, Donnay I, Thompson JG. 1998. Human assisted conception: a cautionary tale. Lessons from domestic animals. Hum Reprod, 13:184-202.

Leese HJ, Sturmey RG, Baumann CG, McEvoy TG. 2007. Embryo viability and metabolism: Obeying the quiet rules. Hum Reprod, 22:3047-3050.

Leibo S. 1983. A one-step in situ dilution method for frozen thawed bovine embryos. Cryo-letters, 4:387-400.
Li S, Winuthayanon W. 2017. Oviduct: Roles in fertilization and early embryo development. $J$ Endocrinol, 232:1-26.

Lin T, Lee JE, Kang JW, Oqani RK, Cho ES, Kim SB, Il Jin D. 2018. Melatonin supplementation during prolonged in vitro maturation improves the quality and development of poor-quality porcine oocytes via anti-oxidative and anti-apoptotic effects. Mol Reprod Dev, 85:665-681.

Lindner GM, Wright RW, Jr. 1983. Bovine embryo morphology and evaluation. Theriogenology, 20:407416.

Liu L, Trimarchi JR, Keefe DL. 2000. Involvement of mitochondria in oxidative stress-induced cell death in mouse zygotes. Biol Reprod, 62:1745-1753.

Lledo B, Ortiz JA, Morales R, García-Hernández E, Ten J, Bernabeu A, Llácer J, Bernabeu R. 2018. Comprehensive mitochondrial DNA analysis and IVF outcome. Hum Reprod Open, 4:1-9.

Lonergan P, Fair T, Corcoran D, Evans ACO. 2006. Effect of culture environment on gene expression and developmental characteristics in IVF-derived embryos. Theriogenology, 65:137-152.

Lonergan P, Fair T, Forde N, Rizos D. 2016. Embryo development in dairy cattle. Theriogenology, 86:270277.

Lonergan P, Rizos D, Gutierrez-Adan A, Fair T, Boland MP. 2003. Oocyte and embryo quality: Effect of origin, culture conditions and gene expression patterns. Reprod Domest Anim, 38:259-267.

Lu KH, Gordon I, Gallagher M, Mcgovern H. 1987. Pregnancy established in cattle by transfer of embryos derived from invitro fertilization of oocytes matured in vitro. Vet Rec, 121:259-260.

Lundqvist M, Johansson U, Lundkvist O, Milton K, Westin C, Simberg N. 2001. Does pronuclear morphology and/or early cleavage rate predict embryo implantation potential? Reprod Biomed Online, 2:12-16. Luo S, Mao C, Lee B, Lee AS. 2006. GRP78/BiP is required for cell proliferation and protecting the inner cell mass from apoptosis during early mouse embryonic development. Mol Cell Biol, 26:5688-5697.

Mahmoudzadeh AR, Van Soom A, Bols P, Ysebaert MT, de Kruif A. 1995. Optimization of a simple vitrification procedure for bovine embryos produced in vitro: effect of developmental stage, two-step addition of cryoprotectant and sucrose dilution on embryonic survival. J Reprod Fertil, 103:33-39.

Mao L, Lou H, Lou Y, Wang N, Jin F. 2014. Behaviour of cytoplasmic organelles and cytoskeleton during oocyte maturation. Reprod Biomed Online, 28:284-299.

Massip A. 1987. Recent progress in cryopreservation of cattle embryos. Theriogenology, 27:69-79.

Mattos MCC. Vitrificação e congelação de mórulas e blastocistos produzidos in vivo em bos taurus e bos indicus. [In portuguese]. Botucatu, Brazil: Universidade Estadual Paulista "Júlio de Mesquita Filho". Dissertation.

May-Panloup P, Chretien MF, Jacques C, Vasseur C, Malthiery Y, Reynier P. 2005. Low oocyte mitochondrial DNA content in ovarian insufficiency. 
Hum Reprod, 20:593-597.

Mazur P. 1980. Fundamental aspects of the freezing of cells, with emphasis on mammalian ova and embryos. In: International Congress on Animal Reproduction and Artificial Insemination. Proceedings of International Congress of Animal Reproduction and Artificial Insemination, pp.99-114.

McEvoy TG, Sinclair KD, Young LE, Wilmut I, Robinson JJ. 2000. Large offspring syndrome and other consequences of ruminant embryo culture in vitro: Relevance to blastocyst culture in human ART. Hum Fertil, 3:238-246.

Merton S, 2002. Morphological Evaluation of Embryos in Domestic Species. In: Van Soom A, Boerjan M. (Ed.) Assessment of Mammalian Embryo Quality. Springer Science+Business Media Dordrecht, pp429.

Miller DJ, Eckert JJ, Lazzari G, DuranthonRichoux V, Sreenan J, Morris D, Galli C, Renard JP, Fleming TP. 2003. Tight junction messenger RNA expression levels in bovine embryos are dependent upon the ability to compact and in vitro culture methods. Biol Reprod, 68:1394-1402.

Misirlioglu M, Page GP, Sagirkaya H, Kaya A, Parrish JJ, First NL, Memili E. 2006. Dynamics of global transcriptome in bovine matured oocytes and preimplantation embryos. Proc Natl Acad Sci U S A, 50:18905-18910.

Mogas T. 2019. Update on the vitrification of bovine oocytes and in vitro-produced embryos. Reprod Fertil Dev, 31:105-117.

Mondou E, Dufort I, Gohin M, Fournier E, Sirard MA. 2012. Analysis of microRNAs and their precursors in bovine early embryonic development. Mol Hum Reprod, 18:425-434.

Mucci N, Aller J, Kaiser GG, Hozbor F, Cabodevila J, Alberio RH. Effect of estrous cow serum during bovine embryo culture on blastocyst development and cryotolerance after slow freezing or vitrification. Theriogenology, 65:1551-1562.

Munoz M, Uyar A, Correia E, Diez C, FernandezGonzalez A, Caamano JN, Martinez-Bello D, Trigal B, Humblot P, Ponsart C, Guyader-Joly C, Carrocera S, Martin D, Marquant Le Guienne B, Seli E, Gomez E. 2014. Prediction of pregnancy viability in bovine in vitro-produced embryos and recipient plasma with Fourier transform infrared spectroscopy. J Dairy Sci, 97:5497-5507.

Nagai K, Yanagawa Y, Katagiri S, Nagano M. 2015. Fertilizability of oocytes derived from Holstein cows having different antral follicle counts in ovaries. Anim Reprod Sci, 163:172-178.

Nagano M. 2019. Acquisition of developmental competence and in vitro growth culture of bovine oocytes. J Reprod Dev, in press.

Nedambale TL, Dinnyés A, Groenc W, Dobrinsky JR, Tiana XC, Yanga X. 2004. Comparison on in vitro fertilized bovine embryoscultured in KSOM or SOF and cryopreservedby slow freezing or vitrification. Theriogenology, 62:437-449.

O'Kearney-Flynn M, Wade M, Duffy P, Gat V, Boland MP, Dobrinsky JR. 1998. Effect of cryopreservation on IVP cattle embryo development in vitro and in vivo. Theriogenology, 49:173

Overstrom EW, Duby RT, Dobrinsky JR, Robb JM, Baguisi A, Lonergan P. 1993. Cytoskeletal damage in vitrified or frozen bovine embryos. Theriogenology, 39:276.

Overström EW. 1996. In vitro assessment of embryo viability. Theriogenology, 45:3-16.

Paschoal DM, Sudano MJ, Guastali MD, Dias Maziero RR, Crocomo LF, Ona Magalhaes LC, da Silva Rascado T, Martins A, da Cruz LandimAlvarenga F. 2014. Forskolin effect on the cryosurvival of in vitro-produced bovine embryos in the presence or absence of fetal calf serum. Zygote 22:146-157.

Pereira RM, Baptista MC, Vasques MI, Horta AE, Portugal PV, Bessa RJ, Silva JC, Pereira MS, Marques CC. 2007. Cryosurvival of bovine blastocysts is enhanced by culture with trans-10 cis-12 conjugated linoleic acid (10t,12c CLA). Anim Reprod Sci, 98:293301.

Pero ME, Zullo G, Esposito L, Iannuzzi A, Lombardi P, De Canditiis C, Neglia G, Gasparrini B. 2018. Inhibition of apoptosis by caspase inhibitor ZVAD-FMK improves cryotolerance of in vitro derived bovine embryos. Theriogenology, 108:127-135.

Perry G. 2016 Statistics of embryo collection and transfer in domestic farm animals. International embryo technology society. 2017. Available from: https://www.iets.org/pdf/comm_data/IETS_Data_Retrie val_Report_2016_v2.pdf. Accessed in: May 10th. 2019. Peterson AJ, Lee RS. 2003. Improving successful pregnancies after embryo transfer. Theriogenology, 59:687-97.

Phillips T. 2008. Non-coding RNA and Gene Expression. Nature Education, 1:115.

Ralston A, Rossant J. 2008. Cdx2 acts downstream of cell polarization to cell-autonomously promote trophectoderm fate in the early mouse embryo. Dev Biol, 313:614-629.

Ramos-Ibeas P, Heras S, Gómez-Redondo I, Planells B, Fernández-González R, Pericuesta E, LagunaBarraza R, Pérez-Cerezales S, Gutiérrez-Adán A. 2019. Embryo responses to stress induced by assisted reproductive technologies. Mol Reprod Dev, 1-15.

Räty M, Ketoja E, Pitkänen T, Ahola V, Kananen K, Peippo J. 2011. In vitro maturation supplements affect developmental competence of bovine cumulus-oocyte complexes and embryo quality after vitrification. Cryobiology, 63:245-255.

Rizos D, Clemente M, Bermejo-Alvarez $P$, De La Fuente J, Lonergan P, Gutiérrez-Adán A. 2008. Consequences of in vitro culture conditions on embryo development and quality. Reprod Domest Anim, 43:4450

Rizos D, Ward F, Duffy P, Boland MP, Lonergan P. 2002. Consequences of bovine oocyte maturation, fertilization or early embryo development in vitro versus in vivo: Implications for blastocyst yield and blastocyst quality. Mol Reprod Dev, 61:234-248.

Rodgaard T, Heegaard PM, Callesen H. 2015. Noninvasive assessment of in-vitro embryo quality to improve transfer success. Reprod Biomed Online, 31:585-592. 
Salilew-Wondim D, Holker M, Rings F, Ghanem N, Ulas-Cinar M, Peippo J, Tholen E, Looft C, Schellander K, Tesfaye D. 2010. Bovine pretransfer endometrium and embryo transcriptome fingerprints as predictors of pregnancy success after transfer. Physiological Genomics, 42:201-218.

Sanches BV, Lunardelli PA, Tannura JH, Cardoso BL, Pereira MH, Gaitkoski D, Basso AC, Arnold DR, Seneda MM. 2016. A new direct transfer protocol for cryopreserved IVF embryos. Theriogenology, 85:1147-1151.

Sanches BV, Marinho LS, Filho BD, Pontes JH, Basso AC, Meirinhos ML, Silva-Santos KC, Ferreira CR, Seneda MM. 2013. Cryosurvival and pregnancy rates after exposure of IVF-derived bos indicus embryos to forskolin before vitrification. Theriogenology, 80:372-377.

Santos P, Chaveiro A, Simões N, Moreira da Silva F 2008. Bovine oocyte quality in relation to ultrastructural characteristics of zona pellucida, polyspermic penetration and developmental competence. Reprod Domest Anim., 43:685-689.

Sata R, Tsujii H, Abe H, Yamashita S, Hoshi H. 1999. Fatty acid composition of bovine embryos cultured in serum-free and serum-containing medium during early embryonic development. J Reprod Dev, 45:97-103.

Schaefer AM, McFarland R, Blakely EL, He L, Whittaker RG, Taylor RW, Chinnery PF, Turnbull DM. 2008. Prevalence of mitochondrial DNA disease in adults. Ann Neurol, 63:35-39.

Schatten H, Sun QY, Prather R. 2014. The impact of mitochondrial function/dysfunction on IVF and new treatment possibilities for infertility. Reprod Biol Endocrinol, 12:111.

Schrode N, Xenopoulos P, Piliszek A, Frankenberg S, Plusa B, Hadjantonakis AK. 2013. Anatomy of a blastocyst: cell behaviors driving cell fate choice and morphogenesis in the early mouse embryo. Genesis, 51:219-233.

Sirard MA, Richard F, Blondin P, Robert C. 2006. Contribution of the oocyte to embryo quality. Theriogenology, 65:126-136.

Spikings EC, Alderson J, St John JC. 2006 Transmission of mitochondrial DNA following assisted reproduction and nuclear transfer. Hum Reprod Update, 12:401-415

Spikings EC, Alderson J, St John JC. 2007. Regulated mitochondrial DNA replication during oocyte maturation is essential for successful porcine embryonic development. Biol Reprod, 76:327-335.

St John JC, Facucho-Oliveira J, Jiang Y, Kelly R, Salah R. 2010. Mitochondrial DNA transmission, replication and inheritance: a journey from the gamete through the embryo and into offspring and embryonic stem cells. Hum Reprod Update, 16:488-509.

Stephenson RO, Rossant J, Tam PP. 2012 Intercellular Interactions, Position, and Polarity in Establishing Blastocyst Cell Lineages and Embryonic Axes. Cold Spring Harb Perspect Biol, 4:a008235.

Sudano MJ, Caixeta ES, Paschoal DM, Martins A, Machado R, Buratini J, Landim-Alvarenga FDC. 2013a. Cryotolerance and global gene-expression patterns of Bos taurus indicus and Bos taurus taurus in vitro- and in vivo-produced blastocysts. Reprod Fertil Dev, 26:1129-1141.

Sudano MJ, Marinho LSR, Costa CB, Cancian R. 2016b. Cryopreservation of Bovine Embryos. In: Seneda MM, Silva-Santos KC, Marinho LSR (Ed.). Biotechnology of Animal Reproduction. Hauppauge, NY, USA: Nova Science Publishers. p.1-33

Sudano MJ, Marinho LSR, Silveira JC, Basso AC, Bohrer R, Lamberti GSE, Watanabe YF, Seneda MM, Meirelles FV. Evolução aplicada da produção in vitro de embriões bovinos. In Gonçalves PBD, Figueiredo JR, Gasperin BG. (Ed.) Biotécnicas aplicadas à reprodução animal, 2019, 3 ed. Grupo Gen, in press.

Sudano MJ, Paschoal DM, da Silva Rascado T, Magalhães LCO, Crocomo LF, de Lima-Neto JF, da Cruz Landim-Alvarenga F. 2011. Lipid content and apoptosis of in vitro-produced bovine embryos as determinants of susceptibility to vitrification. Theriogenology, 75:1211-1220.

Sudano MJ, Paschoal DM, Maziero RRD, Rascado TS, Guastali MD, Crocomo LF, Magalhães LCO, Monteiro BA, Martins Jr A, Machado R, LandimAlvarenga FDC. 2013b. Improving postcryopreservation curvival capacity: an embryo-focused approach. Anim Reprod, 10:160-167

Sudano MJ, Rascado TD, Tata A, Belaz KR, Santos VG, Valente RS, Mesquita FS, Ferreira CR, Araujo JP, Eberlin MN, Landim-Alvarenga FD. 2016a. Lipidome signatures in early bovine embryo development. Theriogenology, 86:472-484.

Sudano MJ, Santos VG, Tata A, Ferreira CR, Paschoal DM, Machado R, Buratini J, Eberlin MN, Landim-Alvarenga FDC. 2012. Phosphatidylcholine and Sphingomyelin Profiles Vary in Bos taurus indicus and Bos taurus taurus In Vitro- and In Vivo-Produced Blastocysts. Biol Reprod, 87:1-11.

Tan K, An L, Wang SM, Wang XD, Zhang ZN, Miao K, Sui LL, He SZ, Nie JZ, Wu ZH, Tian JH. 2015. Actin Disorganization Plays a Vital Role in Impaired Embryonic Development of In Vitro-Produced Mouse Preimplantation Embryos. PLoS One, 10:e0130382.

Thompson JG, Brown HM, Sutton-McDowall ML. 2016. Measuring embryo metabolism to predict embryo quality. Reprod Fertil Dev, 28:41-50.

Thouas GA, Trounson AO, Jones GM. 2005. Effect of female age on mouse oocyte developmental competence following mitochondrial injury. Biol Reprod, 73:366-373.

Thouas GA, Trounson AO, Wolvetang EJ, Jones GM. 2004. Mitochondrial dysfunction in mouse oocytes results in preimplantation embryo arrest in vitro. Biol Reprod, 71:1936-1942.

Tripurani SK, Wee G, Lee KB, Smith GW, Wang L Jianboyao. 2013. MicroRNA-212 post-transcriptionally regulates oocyte-specific basic-helix-loop-helix transcription factor, factor in the germline alpha (FIGLA), during bovine early embryogenesis. PLoS One, 8:e76114. 
Ushijima H, Yamakawa H, Nagashima H. 1999. Cryopreservation of bovine pre-morula-stage in vitro matured/in vitro fertilized embryos after delipidation and before use in nucleus transfer. Biol Reprod, 60:534539.

Vajta G, Holm P, Kuwayama M, Booth PJ, Jacobsen H, Greve T, Callesen H. 1998. Open pulled straw (OPS) vitrification: a new way to reduce cryoinjuries of bovine ova and embryos. Mol Reprod Dev, 51:53-58. Vajta G, Hyttel P, Callesen H. 1997. Morphological changes of in-vitro-produced bovine blastocysts after vitrification, in-straw direct rehydration, and culture. Mol Reprod Dev, 48, 9-17.

Vajta G, Kuwayama M. 2006. Improving cryopreservation systems. Theriogenology, 65:236-244.

Van Blerkom J. 2004. Mitochondria in human oogenesis and preimplantation embryogenesis: engines of metabolism, ionic regulation and developmental competence. Reproduction, 128:269-280.

Van Meer G, Voelker DR, Feigenson GW. 2008 Membrane lipids: Where they are and how they behave. Nat Rev Mol Cell Biol, 9:112-124.

Van Soom A, Boerjan M, Ysebaert MT, De Kruif A. 1996. Cell allocation to the inner cell mass and the trophectoderm in bovine embryos cultured in two different media. Mol Reprod Dev, 45:171-182.

Van Soom A, Mahmoudzadeh AR, Christophe A, Ysebaert MT, de Kruif A. 2001. Silicone oil used in microdrop culture can affect bovine embryonic development and freezability. Reprod Domest Anim, 36:169-176.

Van Soom A, Mateusen B, Leroy J, De Kruif A. 2003. Assessment of mammalian embryo quality: what can we learn from embryo morphology? Reprod Biomed Online, 7:664-670.

Van Soom A, Ysebaert MT, de Kruif A. 1997. Relationship between timing of development, morula morphology, and cell allocation to inner cell mass and trophectoderm in in vitro-produced bovine embryos. Mol Reprod Dev, 47:47-56.

Van Wagtendonk-de Leeuw AM, den Daas JH, Rall WF. 1997. Field trial to compare pregnancy rates of bovine embryo cryopreservation methods: vitrification and one-step dilution versus slow freezing and three step dilution. Theriogenology, 48:1071-1084

Van Wagtendonk-De Leeuw AM1, Den Daas JH,
Kruip TA, Rall WF. 1995. Comparison of the efficacy of conventional slow freezing and rapid cryopreservation methods for bovine embryos. Theriogenology, 32:157-167.

Viana JH. 2018. A produção de embriões bovinos em 2017: o mercado em stand-by. Jornal o embrião, 62:6-10.

Wai T, Ao A, Zhang X, Cyr D, Dufort D, Shoubridge EA. 2010. The role of mitochondrial DNA copy number in mammalian fertility. Biol Reprod, 83:52-62.

Wakefield SL, Lane M, Mitchell M. 2011. Impaired mitochondrial function in the preimplantation embryo perturbs fetal and placental development in the mouse. Biol Reprod, 84:572-580.

Walker SK, Hartwich KM, Seamark RF. 1996. The production of unusually large offspring following embryo manipulation: Concepts and challenges. Theriogenology, 45:111-120.

Wang H, Dey SK. 2005. Lipid signaling in embryo implantation. Prostaglandins and Other Lipid Mediators, 77:84-102.

Ward F, Enright B, Rizos D, Boland M, Lonergan P. 2002. Optimization of in vitro bovine embryo production: effect of duration of maturation, length of gamete co-incubation, sperm concentration and sire. Theriogenology, 57:2105-2117.

Warzych E, Wrenzycki C, Peippo J, Lechniak D. 2007. Maturation medium supplements affect transcript level of apoptosis and cell survival related genes in bovine blastocysts produced in vitro. Mol Reprod Dev, 74:280-289.

Whittingham D, Leibo S, Mazur P. 1972. Survival of mouse embryos frozen to-196 and-269 C. Science, 178:411-414

Wrenzycki C, Stinshoff H. 2013. Maturation environment and impact on subsequent developmental competence of bovine oocytes. Reprod Domest Anim, 48:38-43

Xu J, Guo Z, Su L, Nedambale TL, Zhang J, Schenk J, Moreno JF, Dinnyes A, Ji W, Tian XC, Yang X, Du F. 2006. Developmental potential of vitrified holstein cattle embryos fertilized in vitro with sexsorted sperm. J Dairy Sci, 89:2510-2518.

Yu XL, Deng W, Liu FJ, Li YH, Li XX, Zhang YL, Zan LS. 2010. Closed pulled straw vitrification of in vitro-produced and in vivo-produced bovine embryos. Theriogenology, 73:474-479. 